\title{
Abbreviations and American slang
}

\section{FÉLIX RODRÍGUEZ GONZÁLEZ}

\author{
A survey of the acronyms and other types of \\ abbreviation used among students, soldiers, \\ nurses, hobos and others in the USA
}

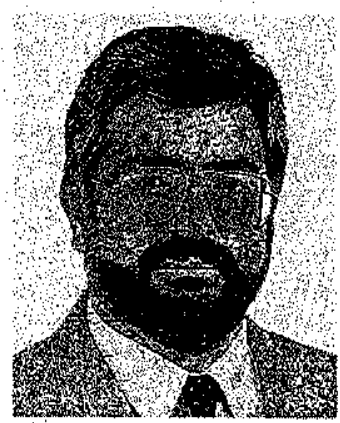

ABBREVIATIONS, especially those formed by initials ('acronyms'), constitute one of the most striking features of today's language. In an era characterized by constant technological changes and an influx of organizations of various kinds, the phenomenon of abbreviation provides an easy way out for terminological needs. If language has always been prone to linguistic economy, if speakers and writers tend to be concise and precise, this need is much more strongly felt in the face of the complex phrases and denominations which are continuously created to name new realities.

Expressions thus formed no doubt give language a formal and jargonesque air, but in addition to this highly technical and aseptic terminology, we also find terms of a very different kind in the speech of many occupational and social groups. These abbreviations are colloquial and informal, and commonly typified as 'slang', as they are primarily meant to fulfil expressive or emotive needs and to create a sense of identity within a group. To illustrate this point I will present many examples from English slang, especially from its American variety.

\section{A brief look at the past}

Abbreviations with a familiar and slang use have been in the language from an early stage.
The first wave of initials in speech which is known to us dates from 1838 and occurred in Boston, from where it spread in successive years to New York and other parts of America. From that period we can date the still current and internationally familiar OK (all correct) as well as others frequently used then like N.G. (no go), K.O. (kicked out), K.H.O. (kick him out), L.L. (liver loafers), G.T. (gone to Texas), P.D.Q. (pretty damn quick), O.F.M. (our first men: used with a certain satirical intention). In most cases they were markedly humorous colloquial expressions which spread to all areas of society, as is acknowledged by a New York newspaper of

FÉLIX RODRÍGUEZ is Associate Professor of English at the University of Alicante in Spain. He holds a doctorate in Romance Linguistics from the University of Alberta (Canada) and of English Philology from the University of Salamanca (Spain). He has published numerous articles on lexicology and sociolinguistics, which he teaches at the University of Alicante. He has published books on slang

('Comunicación y lenguaje juvenil', Madrid, 1989) and political language ('Prensa y lenguaje politico', Madrid, 1991) and he is currently writing a book on English and Spanish acronyms. He is a member of the executive committee of an intemational associazion dedicated to the study of slang known as CEPLAFE (La Sorbonne, Paris). 
the time, Evening Tatler (27/7/1839, p.2/2), and recorded by Allen Walker Read:

THE INITIAL, LANGUAGE. - This is a species of spoken short-hand, which is getting into very general use among loafers and gentlemen of the fancy, besides Editors, to whom it saves, by its comprehensive expressiveness, much trouble in writing and many 'ems' in printing ( . . .).

A similar humorous and familiar tinge is present in most of the letter abbreviations (or 'initialisms') compiled by F. W. Long at the beginning of this century, although, actually, some of them were used earlier in the second half of the 19th, among which one may mention w.c. (water closet). f.h.b. (family hold back), f.s.e. (family stop eating), m.i.k. (more in the kitchen), s.y.h. (see you home), s.y.l. (see you later). These initials were especially used in the highest social strata and had, at least at an early stage, an intimate and quasi-secret use.

Besides these colloquial phrases of general use in the first and second half of the 19th century (a relatively short-lived and isolated phenomenon) by the close of the second half and the beginning of the 20th, as technical and institutional acronyms started to become established, the system of initials was invading the special langtuages or slangs of the most diverse professional and social groups of America and of Britain. A look at the extensive and well-known monographic study on slang by Eric Partridge (Slang To-day and Yesterday), brings up the following: from the slang of commerce, L.L. (Limited Liability), used satirically to suggest fraud, and R.M.D. (Ready Money Down); among literary critics, D.T. Centres was the name given to some bohemian literary, social and artistic clubs (D.T.'s meaning deliritu tremens); to student slang belonged Elsie, a nickname for the East London College, and B.M.; or B Emma, which was the short form for British Museum, used to express the irritation caused by waiting for the delivery of books in the library of the British Museum; from medical slang came B.B.A. (born before arrival), used by midwives (usually to express relief at being spared a troublesome delivery), and B.I.D. (brought in dead), in reference to a casualty who is dead on arrival at the operating theatre; among politicians, G.O.M. meant Grand Old Man; in some social clubs, as in well-to-do society, A.D. (a drink) was uised as an excuse for a man to get away from a dance by inviting his dancing partner to have a drink with him instead, and N.D. was applied satirically to a woman who tried to look much younger that she really was (the name comes from the jargon of librarians where N.D. (no date) referred to a book which lacked the date of publication).

\section{The extension of the phenomenon}

From the above examples it seems as if this type of acronym was linked with the refined classes of society. However true this might have been at first, which would be quite understandable in the light of the characteristically leanned flavour of the acronyms, the use of initials is also practised among the most marginal and uncultured sectors where they are often used with cryptic purposes. Glossaries on the usage of American hobos from the beginning of the century include, for example, $C$ and $A$ pocket (a pocket cut into the back lining of a coat to hold parcels of food), $C . H$. and $D$. (cold, hungry and dry), and $L . S$. and $M$.S. (less sleep, more speed).

A cryptic and/or euphemistic intention also lies behind the formation of acronyms used in the modern language of drugs (C or cee for cocaine; $\mathrm{M}$ or $\mathrm{MJ}$ for marijuana; $\mathrm{AD}$ and $\mathrm{DA}$ for drug addict; to OD, to take an overdose), sex (AC/DC, altemating current and direct current for bisexual; TV (transvestism) training; $T$ and $A$ for tits and ass) and delinquency (POV, privately owned vehicle 'stolen', C-gee for confidence (game) man, and $\mathrm{HBI}$ for housebreaking implements).

There are cases when the wish to hide the meaning can lead to well-known initials undergoing further elaboration, as happens in the slang of drugs. The expanded abbreviation can take the form of ordinary words (candie for $\mathrm{C}=$ cocaine; hot and cold for $\mathrm{H}$ and $\mathbf{C}=$ heroine and cocaine), phrases (let sunshine do and Lucy in the Sky with Diamonds for L.S.D.) and, more commonly, names of persons (Carrie, Cecil and Charlie for $\mathrm{C}=$ cocaine; Henry and Aunt Hazel for $\mathrm{H}=$ heroine; Mary and $\mathcal{F}$ ane for $M$ or $\mathrm{J}=$ marijuana; Miss Morph and Aunt Emma for $\mathrm{M}=$ morphine; Aunt Nora for $\mathrm{N}=$ narcotics).

Acronyms in American English are rather striking because of their number and their frequency of use, not only in specialized technical terminology - easy to explain in 
view of the hegemony of the United States in so many fields - but also as a result of the various argots, or slangs, as well as the number of acronyms which have a slang or expressive function in them. In order to give a clear idea of the extent to which the abbreviatory system has penetrated the speech of these groups; I will focus on three of them (students, soldiers and nurses) which seem to be highly representative.

\section{The slang of students}

The tendency of students to abbreviate was pointed out long ago by W. E. Schultz in a brief monograph, 'College Abbreviations' (American Speech, 1929, pp. 240-41). Apart from mentioning the desire for brevity, the author implicitly recognizes the expressive properties of abbreviations by attributing their existence also "to a desire for a more intimate term for common use', to which he adds, among other comments:

The college student is at heart a sentimentalist, and the abbreviations of his campus generation (a short period of four years) become traditions that are as dear to his heart as the scenes of his childhood . . . College abbreviations, once created, properly lodged, and adopted, are rarely discarded, unlike the slang words or phrases of the campus. They become, in a sense, slang words, but they possess sturdy vitality . . . The college student has, of course, an artistic faculty, and an uncanny impulse, to abbreviate everything he says or writes.

However, the lexicon compiled in Schultz's article consists mainly of clipped words, and the few initials collected refer to the basic institutions of university life, like personnel, places, organizations, etc. More peculiar and recent, and more significant for our purpose, are the following acronyms picked out from a variety of studies: AKA (alcohol kills all), B.M.O.C. (big man on campus), D (decibel for noise), D.A.R. (darn average raiser), GAPO (giant armpit odor), G.D.I. (Goddamned independent), G.D.J. (God-damned jewel), K.K. (campus cops), n.s. (no shit), P.T. (prick teaser), R.F. (rat fuck: used as a verb to mean to have a good time or do something with no particular purpose), Saigon $U$ (University), in ironical reference to those who supposedly had to go to Vietnam after having failed their exams, S.F.B. (shit for brains), TGIF (Thank God it's Friday), used attributively of a party due to celebrate the arrival of the weekend and from which the term giffed ('drunk') has been derived.

In some of these acronyms, we can see that expressions of appraisal and intensification are frequent; this is a constant feature of youth language in general, as is also the discourteous and ridiculous tone which fits well with the negative and antisocial attitude exhibited, although this attitude is often no more than a pose.

\section{The slang of soldiers}

Another group prone to developing a rich slang are soldiers. The vigour and picturesqueness of their lexicon is closely related to the enclosed, isolated or even remote situation which characterizes the daily life of recruits, in addition to the constant stress produced by hard discipline and at times, the threat of war; not to mention real war which, in the words of Partridge, constitutes ' $a$ powerful excitant, perhaps the most rapidly effectual excitant of language'.

The special conditions of military service are reflected in the vocabulary of acronyms, as is indicated by the terms which follow (drawn from a number of glossaries): BAM (broad-assed marine $=$ a female serving in the Corps), D.P. (daisy pusher: a dead man), FIGMO (Fuck it - got my orders), IHTFP ( hate this fucking place), N.B.G. (no blankety good/no bloody good), P. and P. (piss and punk), P.O.'d (pissed off: angry, irritated), $P$. and $S$. (pick and shovel), SNAFU (or snafu: 'situation normal, all fucked up'), S.O.L. (shit/surely/soldier out of luck), SOOL (sadly out of luck), SOS (same old slum/stew/stuff/shit; also shit on a shingle, a piece of toast with minced meat and cream), WW (wild woman: a girl from a cabaret, a prostitute, etc.), YMCA (you must come across/your money cheerfully accepted, with a sarcastic reference to the custom of overcharging the soldiers).

One of the features which best define these terms is obscenity and vulgarity. However offensive and shocking they may sound, from a psychological point of view they are important inasmuch as they provide a strong tie between people from very different social backgrounds by giving them a common ground of personal relationship; if anyone breaks this rule it might be interpreted as a 


\title{
The triumph of the TLAs
}

\author{
HUMPHREY EVANS of London takes a light-hearted look at \\ a fashionable species of abbreviation.
}

Look out folks. We're being hit by a shower of TLAs. That's Three Letter Acronyms to the uninitiated.

Computer buffs have got a lot to answer for. If you put in time at your VDU (Visual Display Unit), experimenting with DTP (Desk Top Publishing), you may end up with RSI (Repetitive Strain Injury). Executive wives, committed to following their husbands to pasts around the world, know that IBM stands for I've Been Moved.

The military are heavily involved, as the Gulf War reminded us with those MREs: Meals Ready to Eat or Rejected by Ethiopians, depending on whether you were cooking or consuming. They may have something to do with NDEs (Near Death Experiences), though that might more easily apply to the latest roller-coaster rides or some of the things that go on in hospitals.

Doctors do succumb. Remember the days of TLC (Tender Loving Care)? Perhaps you didn't know that the prescription guaranteed to see off time-wasting patients was ADT (Any Damn Thing, so long as it came in a bottle, smelt foul and tasted even worse).

Older acronymists are used to doing things PDQ (Pretty Damn Quick), or seeing their reports consigned to the WPB (Waste Paper Basket). They may even be looking forward to an $\mathrm{OBE}$ (recognition based on some Other Bugger's Efforts).

The Queen may know about those but maybe not the other kind of OBEs (Out of Body
Experiences), beloved by UFO-watching New Age spiritualists. She certainly was not involved with the plague of PSWs (Phantom Social Workers) so many newspapers reported as attempting to abduct children.

Minnesota Mineral and Mining, the company that brings you those yellow Post-it notes, has reduced its name to $3 \mathrm{M}$, which doesn't quite count but does put it on the first page of the phone book. It still has to deal with Working Women Worldwide, stuck with WWW as an unwieldy moniker. Even gang members in Los Angeles have turned to TLAs, spraypainting sidewalks and buildings with the letters FTL (Fuck the Law). While a television evangelist preached PTL (either Praise The Lord or People That Love), cynical outsiders held that the numerous calls to send donations should have transmuted it to Pass the Loot.

Meanwhile, FWBs (Friends with Babies) suddenly stop talking about politics, art and sex, discussing instead the mushy food and mushier by-products that go in and come out of their adored children.

Unions as a whole have joined in gaily. MSF (Manufacturing, Science \& Finance) still retains some kind of relevance, but how many people appreciate that the $B$ in the title of the British mega-union GMB stands for Boilermakers?

Perhaps this is the real reason the SDP collapsed in Britain. It just became the first identifiable victirn of TLA abuse. RIP. wish to feel superior and as a result they would be ostracized, which would eventually upset the feeling of togetherness and create uneasiness on both sides. The use of such terms in acronym form is to some extent an answer to the need to caricature military language for being far too artifical, cryptic and telegraphic.

\section{The slang of nurses}

Finally, I emphasize hospital slang, in particular that spoken by nurses. Most of the authors who have studied it have pointed out the great number of abbreviations and acro- nyms it contains. This is so great that P. C. Kolin, one of the people who have paid most attention to this subject, distinguishes two subtypes of vocabulary, namely, slang and nonstandard abbreviations; of the latter he confines himself to collecting only the abbreviations and acronyms of general circulation since he thinks that the compilation of all the idiosyncratic uses of each hospital would be an impossible and unnecessary task.

Closely connected with hospital language are medical abbreviations as a whole, which constitute an extensive repertoire that has given rise to the publication of some dictionaries; for instance, Peter et al. Roody, Medi- 
cal Abbreviations and Acronyms, New York McGraw-Hill, 1976; and Harold Hughes (ed.), Dictionary of Abbreviations in Medicine and Health Sciences, 1977. It is obvious that these acronyms have in the main a technical character, especially if compared with the ones pertaining to the special languages already mentioned, of students and soldiers. According to Partridge, medical acronyms are generally 'jargon' (or technical language), as distinct from clipped words which are basically 'slang' (i.e. expressive language), and he considers that 'in medicine there are relatively few true slang expressions, although many words and phrases are used [that are] incomprehensible to the layman.'

Nonetheless, in the light of our times and with regard to the language of nurses in America, it would be difficult to substantiate these positions. It is generally believed that humorous, pejorative and euphemistic words are very appropriate linguistic means of expressing or relieving strain. As it might be expected, such features are present in hospital slang as it is used by staff who face suffering every day and must carry out demanding activities under the pressure of time. Thus one can explain why nurses' slang is, as Kolin suggests, 'a curious blend of the banal and the medically exact, the pretentious and the comic' ('More Nursing Words', American Speech, 55, 1, 1980). Among the acronyms quoted by this author are: HS (horae somni for hours of sleep), FX (fracture), KJ (knee jerk), LOS (length of stay), NB (new born), SB (stillborn), MOM (milk of magnesia), SOAP (subjective objective assessment plan, used to describe the treatment followed by the patient), SOB (short of breath), SOOB (sit out of bed), TNT (too numerous to count), VIP rooms (luxury large roorns). Other studies include still more expressive acronyms, such as C.O.P. (crochety old patient), $4 F^{\prime} \mathrm{er}$ (fat, fertile, fortyish, female), F.L.K. (funny looking kid), L.O.L. (little old lady), shpos (subhuman piece of shit). These acronyms are doubly interesting since they belong to slang related to patients, which it has been suggested, is not particularly prone to expressiveness.

\section{Reasons for the use of slang}

The presence of this type of acronym in American English is not limited to social groups as large and important as those described; it also reaches the speech of rather restricted or minority groups. Thus in the language of barbers with musical interests compiled by D. J. Richardson, out of 182 entries, over $20 \%$ are acronyms. Acronyms and abbreviations of all types are likewise an important element in the peculiar style of the readers of fanzines (fan magazines), especially those related to the TV series 'Star Trek' which has given rise to the publication of a work significantly entitled The Strekfan's Glossary of Abbreviations and Slanguage (Toledo, Ohio: Kzinti Press, 1976).

On the one hand, the use of such an enormous flood of acronyms by such restricted groups and, on the other, the frequency with which the various slangs turn to acronyms made out of rather short phrases, or having a similar phonetic shape (which would prevent us from speaking strictly of abbreviation in the sense of phonetic reduction) are a good indication that in addition to the pressure to economize pressures - essential in the shaping and consolidation of the initials system - there are, not infrequently, factors of a functional-expressive type. To these two motives may be added the fact that their use is felt as a sign of prestige: it reveals that the user is 'in the know', and this knowledge acts as a semiotic signal, as it allows him to be distinguished as a member of a group or subculture. This is all the more evident when the expression is restricted in its use, its register is informal and its functional or expressive motivation is clear.

The expressiveness is more obvious when the connotation of the phrase is pejorative. According to some authors, pejorative expressiveness is an inherent condition of slang and it includes such expressive tones as scorn, irony, contempt, mockery, and jocularity. The pejorative tinge is especially notable when the source of the acronym is in itself a coarse and offensive expression, as has been amply exemplified. But this is not a necessary prexequisite as demonstrated by WASP (White Anglo-Saxon Protestant) and G.I. (Government Issue), which in military slang is a synonym of soldier but has been used by officers rather than by recruits on account of its condescending connotations.

More than any other reasons, acronyms in slang are frequently used with clearly humorous purposes following a trend which is 
general in the slang of today. Such is the case of the dysphemistic expressions mentioned above, but humour permeates acronyms of even apparently neutral connotations. The effects can be obtained by different linguistic means:

$O$ on the one hand, by making the acronym homonymous with an already existing word (MOM, SOAP, SOB, in the language of nurses), by providing it with a peculiar sequence of initials (S.K.P., for escaped prisoner, in the jargon of traffic policemen; L.I.Q. for liquor store; H.R.N. for heroine), or by changing its spelling ( $\mathrm{KP}$ for common prostitute, $\mathrm{KO}$ for Commanding Officer in the slang of soldiers) or the order of its initials (A.D. for drug addict);

on the other, by choosing as sources of the acronyms expressions which are metaphoric (DTs, delirium tremens, meaning hangover; TNT, trinitrotoluene [a powerful explosive] for heroine; $\mathrm{ID}$, identification card, for penis), taboo (PITA, pain in the arse, meaning an annoying person; $\mathrm{T}$ and $\mathrm{A}$, for tits and ass) or euphemistic (PDA, public display of affection for kissing, cuddling, necking or petting in public); or which do not readily lend themselves to abbreviation on the basis of their limited or non-existent phonetic reduction (SOOB /es-o-o-bi/ for sit out of bed).

The examples in this article demonstrate the presence and significance of the humorous motivation in slang with acronym shortenings, which are taken to be a work-making device associated with technical neologisms and normally free from connotations. They remind us that acronyms and neologisms in general are not necessarily created to name new concepts; their existence may also be a manifestation of the ludic or playful function of language, evoking the condition of Homo ludens (Huizinga) which so well defines humankind, and especially young people, a feature which has also been reflected here in the typically youthful character of the majority of argots described (students, soldiers, nurses, fanzine readers).

\section{Conclusion}

The choice of slang acronyms of English origin as the basis for this article has not been fortuitous or the result of a personal whim, but arises from their frequent occurence in this language in sharp contrast to the frequency with which they occur in other modern languages like Spanish and the rest of the Romance languages, where their presence is hardly felt. Furthermore, if I have gone into elaborate explanations and given long lists of examples of the slang of some particular groups, my aim was to show the extent of this practice, especially in America. This fact corroborates and underlines the continued relevance of the ideas contained in the following passage written by H. L. Mencken at the beginning of this century:

'American shows its character in a constant experimentation, a wide hospitality to novelty, a steady reaching out for new and vivid forms. No other tongue of modern times admits foreign words and phrases more readily; none is more careless of precedents; none shows a greater fecundity and originality of fancy. It is producing new words of every day, by trope, agglutination, by the shedding of inflections, by the merging of parts of speech, and by sheer brilliance of imagination.'

\section{A common language}

Haidar Abdel Shafi, the bald old professor leading the Palestinians, and Kamel Abu Jaber, the urbane man-of-the-world Jordanian foreign minister, had only one thing in common with Shamir, the grizzled veteran of Israel's struggle for survival: the English language.

They used it to misunderstand one another and to trade insults, sometimes eloquently, quoting Albert Einstein, William Wordsworth, the Koran and the Talmud; but apparently forgetting that the purpose of their meeting was what Winston Churchill described as "jaw-jaw instead of war-war".

(from Peter Millar and Andrew

Hogg, 'Madrid: Anger', The

Sunday Times, 3 Nov 91). 